\title{
PAISAGEM À BEIRA DA PISCINA
}

Na piscina estava sendo realizada a última largada, animada por altos brados. Os corpos de pele bronzeada das nadadoras mergulham um após outro. Quem os persegue é a voz do instrutor.

Uma nadadora, ao subir arrastando-se no posto de largada, permaneceu de bruços, colada ao chão e respirava com dificuldade, ondulando as costas.

Nesse instante, pelo outro lado da piscina, passa um trem fazendo uma leve curva. As pessoas que estão em pé, segurando as alças, são todos assalariados retornando para casa depois de um dia de trabalho.

Do panorama que se descortina inesperadamente, passando o prédio da escola, precipitam aos seus olhos a cor da água que enche a piscina recém-construída e os corpos das nadadoras que estão sobre o concreto.

Esta cena talvez tenha servido de consolo, por instantes, à alma dos pobres trabalhadores abatidos com 0 calor e desanimados por vários problemas.

De um lugar um pouco afastado da animação das nadadoras, um homem de estatura alta está em pé, observando o treino.

É um homem de expressão terna e otimista que vestia um calção de banho e trazia um roupão no ombro.

Ele é o senhor Hiroo Aoki, um ex-aluno e pai de dois meninos que freqüentam atualmente o curso primário desta escola.

(O Sr. Aoki exerce o cargo de chefe substituto de seção de uma certa companhia têxtil.)

Os dois filhos nadam como cachorrinhos na raia do canto, a única que está vaga. $O$ mais velho está no 5 ọ ano e o menor um ano abaixo.

A figura do Sr. Aoki era vista nesta piscina nestes últimos quatro dias, sempre à hora do entardecer. Ele conhecia o instrutor de vista e teve a permissão para fazer o treino de seus filhos, contanto que não atrapalhassem as nadadoras.

As vezes ele também pula cuidadosamente na água, numa postura semelhante à de um canivete meio dobrado, e nada mansamente os 25 metros no estilo crawl. Essas demonstrações revelam muita habilidade.

Porém, demonstrando reserva para com as nadadoras, ele ficava mais tempo à beira da piscina deixando somente as crianças brincarem na água; por vezes, ele dava instruções de nado respondendo ăs 
perguntas dos filhos e, o resto do tempo, ficava contemplando admirado o intenso treinamento das nadadoras.

Logo depois, na cerca da entrada para a piscina aparecia a Sra. Aoki, trazendo um cachorro branco, grande e com espessos pêlos escorridos.

Passados alguns instantes, percebendo a sua presença, o Sr. Aoki chama os dois que brincavam animadamente, espirrando água um no outro. Os filhos são obedientes. Saem rapidamente da piscina e saem correndo para tomar o banho de chuveiro.

O Sr. Aoki, agora usando uma bermuda, agradece ao professor que está batalhando sentado numa cadeira colocada no centro do postó de largada, e sai da piscina atrás dos filhos.

A senhora que esperava por eles perto da cerca cumprimenta o professor dirigindo-Ihe um sorriso, dá a corrente do cachorro para o menino mais velho e, ao lado do marido, toma o caminho de volta pela rua lateral do prédio da escola.

A casa deles situa-se a aproximadamente 200 m desta escola.

O instrutor que acompanhou a família do Sr. Aoki desaparecer à sombra das árvores-da-cera, sentiu-se emocionado, sem qualquer explicação.

(Aquela que é a verdadeira vida. Uma vida digna de ser vivida. Uma familia que pratica um pouco de natação antes do jantar e depois volta para casa. I

A família do $\mathrm{Sr}$ Aoki caminha para casa, pela calçada envolta em crepúsculo, encabeçada por um cachorro grande e branco de pêlos longos e escorridos. O que os espera no lar é uma mesa de jantar alegre e feliz e uma reunião familiar de uma noite de verão.

Mas, não é assim. A este casal, o que o espera é algo diferente. $E$ algo que nem os filhos e nem os vizinhos sabem.

Como denominar a isso?

O Sr. Aoki foi demitido há uma semana. A causa - um desfalque 
que ele cometeu na firma.

O casal é deixado a sós depois que as crianças dormiram.

Estão face a face, descansando nas espreguiçadeiras colocadas no terraço, sob a pérgula de glicínias. Não trocam palavras. Somente espantam vez por outra os pernilongos que pousam em seus pés com a ventarola que têm nas mãos.

A senhora é uma pessoa de estatura miúda e dona de um corpo bem feito. Ao vê-la caminhando pelas ruas, calçando sandálias vermeIhas e com uma sacola de cânhamo numa das mãos, tem-se a nítida impressão de ser uma dona-de-casa jovial e alegre. As vezes podia-se vê-la tomando sorvete numa lanchonete, perto da estação de trem, acompanhada pelo cachorro, ou vê-la rindo alegremente quando, brincando com os seus dois filhos, derrotava-os numa corrida.

Mas com este último acontecimento, ela também levou um grande susto. É como se tivesse tocado um dos joelhos no chão do ringue, numa luta de boxe.

- Afinal, o que foi que você aprontou?

Perguntou, de olhos arregalados ao marido, quando este, voltando para casa atordoado, disse que fora despedido.

Todas as noites, o retorno do marido acontecia sempre perto da meia-noite e eram freqüentes os dias em que chegava de táxi em horas mais avançadas, mas tudo isso se tornara uma rotina que nem a preocupava mais.

Ele dizia que era recepção de clientes, porém isso não iria se repetir por todas as noites e, na certa, muitas vezes voltava tarde por ter ido divertir-se às próprias custas. Não se pode saber o que fazia e nem por onde andava.

Porém, são coisas sobre as quais não adianta nem comentar. Mesmo voltando tarde para casa todas as noites, ele não se mostrava cansado e nem se queixava, não havendo, portanto, por que reclamar.

Como nunca falava sobre a firma, ela também nunca demonstrou interesse, mas ó que teria acontecido para ser despedido tão repentinamente?

- Explicou que usara o dinheiro da firma (o montante equivalia a aproximadamente seis meses de salário do marido) e fora descoberto. Disse que tencionava devolver a quantia, mas que fora denunciado antes de poder fazê-lo.

$\mathrm{Na}$ verdade, teria de reembolsar esse dinheiro mesmo vendendo a casa. No entanto, os dirigentes da firma decidiram que isso năo seria necessário e que, em troca, deveria se afastar imediatamente. 
Afinal, que situação é esta? Trabalhar durante dezoito anos e depois ser dispensado tão sumariamente?

Se o marido estivesse lhe contando uma piada para pregar um susto, a ela, que não se assusta facilmente. Se assim fosse, como seria bom!

Mas ela percebeu que não era nenhuma brincadeira de mau gosto, no instante em que viu o marido entrando no hall da casa. Ela sentiu que alguma coisa de mau agouro estava sobre o ombro dele.

- Não há outra solução?

- Não.

- Não tentou pedir para o Sr. Komori?

- Ele é quem está mais zangado.

O Sr. Komori era o superior com quem o marido mais tinha amizade. Ela mesma já fora muitas vezes à casa dele e havia conversado com a sua esposa.

- E se eu fosse pedir-lhe?

- E inútil, já foi tudo decidido.

Ela se calou e chorou.

Passado o primeiro choque, a calma lhe voltou. Então, ela sentiu como se tivesse deparado com um milagre ante a verdade de que a vida deles, em relação à qual jamais tivera qualquer preocupação, havia desmoronado tão facilmente.

Foi até formidável.

(A vida é assim mesmo.)

Observando friamente os acontecimentos, isto não é algo que foge totalmente à imaginação. $O$ marido nunca foi uma pessoa dedicada ao trabalho. Não é também uma pessoa de princípios rígidos. E um homem que sacrifica tudo para poder beber e se divertir. Como poderia garantir que não cometeria erros?

Mesmo que comesse e bebesse por conta da firma, além das vezes em que recepcionava clientes, isso deveria ter um limite. E mesmo que bebesse por conta própria, seria muito pouco, pelo salário que recebia. Ela fora uma descuidada em permanecer tranqüila, sem nunca ter levantado suspeitas a esse respeito.

O marido também nunca deve ter imaginado que a situação se agravaria tanto, mas a crise já começara quando ele considerou levianamente os fatos. Se tivesse realmente a intenção de reembolsar, era 
uma quantia que poderia ter arranjado sem muita dificuldade. Tudo talvez porque ele jamais tenha sentido profundamente a necessidade de considerar o emprego com seriedade e severidade.

Já faz quinze anos que estão casados e, por nunca ter sentido este tipo de perigo em relação ao marido, ela não se lembrava de the ter pedido para zelar pelo emprego.

Refletindo dessa maneira sobre os fatos, ela se conscientiza novamente de como era verdadeiramente ridicula e instável a vida que o casal levava até hoje. $E$, de repente, o marido que foi despedido, depois de ter chegado ao cargo de chefe substituto, começou a lhe parecer um homem avoado e tolo. Será que ela não achava, no intimo, que o seu marido era um beberrào farrista, mas que por outro lado era um homem trabalhador, na mesma proporção? Será que não houve ocasioes $\mathrm{\epsilon m}$ que se gabou do seu marido diante de suas amigas do tempo de colégio, baseada nesse conceito? Ela se sentiu enraivecida consigo mesma.

De.que modo um homem que foi descartado do emprego aos quarenta anos de idade vai conseguir impor ordem em sua casa? 0 que fará para o ordenamento de sua vida?

Era uma questão em que o desespero sobrepujava qualquer tentativa de raciocínio coerente. No entanto, era algo que não poderia ser ignorado.

Uma lua assustadoramente grande apareceu dentre as folhas do plátano do jardim. A senhora, olhando nessa direçäo, soltou um suspiro quase imperceptível.

As crianças receberam com agrado as súbitas férias do pai.

0 mais velho pede para levar a escalar montanhas e o mais novo diz que quer coletar insetos.

- Não. Papai tem que ficar em casa repousando, pois está muito cansado.

Dizendo assim, ela acalmava os filhos. 0 marido, sorrindo timidamente, dizia:

- E isso mesmo. Papai está precisando de descanso. Quero que me perdoem por não levá-los desta vez a um passeio mais longo.

As crianças abriram mão de seus pedidos relutantemente. Em compensação, a partir do terceiro dia, resolveram ir nadar na piscina nova da escola, levando o pai à força. $\mathrm{Na}$ verdade não podiam usu. 
fruir a piscina, pois o time de natação do curso colegial feminino estava fazendo uma concentração visando o campeonato inter-colegial de esportes.

Francamente, o Sr. Aoki não tinha ânimo nenhum para pular nas águas de uma piscina. Só se mostrava desanimado, ficando o tempo todo deitado sobre o "tatami", com as longas pernas estendidas. Foi o esforço da esposa que conseguiu, com incentivos, fazê-lo sair de casa levando o calção e o roupão de banho. (Se você continuar desse jeito, daqui a pouco estará doente. Vá nadar para se distrair um pouco.)

O Sr. Aoki sempre foi um amante do esporte. Quando estudante, teve ocasiāo em que foi jogadór de voleibol.

Até então, era freqüente ele jogar beisebol com os filhos nas manhãs de domingo, na rua em frente à casa, e era costume assistir aos campeonatos inter-universitários de rugby acompanhado da esposa e dos filhos.

Por isso, ensinou natação às crianças, levando-as à praia, desde a idade em que ainda engatinhavam.

No primeiro dia, como ainda não tinham voltado mesmo depois de ter aprontado o jantar, ela foi buscá-los e viu que o marido que estava na piscina era bem diferente do homem que havia saído de casa atrás dos filhos.

O marido, de braços cruzados, sem perceber que a esposa viera buscá-los, olhava fixamente para as nadadoras que, treinando o "beat" (treinamento de bater as águas com as pernas), avançavam lenta e pacientemente apoiadas em pedaços de madeira. Observando esse comportamento do marido, ela, com um sentimento lastimável, senão inexplicável, murmurou a si mesmo: "Mas que homem!"

No segundo dia, ela comprou e levou uma caixa de chocolate, com o intuito de agradecer ao instrutor e oferecer como lanche às nadadoras. Chamou o marido para perto da cerca e pediu-lhe que entregasse ao professor.

O marido pegou a caixa de chocolate, foi até o centro do posto de largada onde estava o professor e entregou-a sorrindo cordialmente. O prófessor sorriu, mostrando os dentes brancos e, depois, gritou:

- Ei, para quem diminuir o recorde de tempo, darei o chocolate que ganhamos do Sr. Aoki! Vamos, esforcem-se!

As nadadoras que estavam em volta do professor ficaram agitadas e começaram a gritar: "Isso é crueldade!", "Se me der o chocolate 
primeiro, diminuirei o recorde!"

O marido, observando essa cena com ar de contentamento, sorria ridiculamente.

A caixa de chocolate foi aberta e o seu conteúdo imediatamente distribuído para as nadadoras que se amontoavam em redor do professor Elas, recebendo o chocolate na maior algazarra, agradeciam ao marido e jogavam o doce boca adentro.

Bem que poderia se afastar logo, pensava a esposa, mas o marido não saía de perto das alunas. Aí o professor the ofereceu, dizendo: "Que tal um?" Contudo, isto ele recusou e finalmente retornou para a raia do canto, onde estavam os seus filhos. Observando os atos do marido, ela não sabia dizer se o seu marido era um ingênuo ou um bobo, e acabava experimentando um sentimento estranho e confuso.

$\mathrm{Na}$ hora de ir embora, as nadadoras, de dentro da piscina merguIhada no lusco-fusco, graciosamente mandavam cumprimentos na direção deles: "Tcháu! Muito obrigada pelo chocolate!" Ouvindo isso, o marido, meio sem jeito, respondeu abanando a mão discretamente.

As folhas das árvores-de-cera apresentavam uma misteriosa tonalidade verde, recebendo os últimos raios do entardecer que restaram no céu. Enquanto iam andando sob essas folhas, percebia que o rosto do marido tornava-se gradativamente sombrio. Ela fingia não perceber essa transformação, mas sabia que a sua própria fisionomia também ia demonstrando desânimo.

$\mathrm{Na}$ frente dos dois vão andando os irmãos, puxando o cachorro. As vezes eles chamam o cachorro. Suas vozes fortes soam-lhe de maneira desagradável.

- Conte-me alguma coisa - ela fala. - Se ficarmos calados, começo a ficar déprimida.

- É verdade - diz o marido, como se tivesse despertado. - Sobre o que contarei?

- Sobre as boates.

Ele olha assustado para a esposa.

- Das boates que você costuma freqüentar.

- Não é nada interessante.

- Não faz mal, conte-me. Pensando bem, eu nunca ouvi você falar sobre essas coisas. Sobre esses lugares, como as boates, que você 
costuma freqüentar.

Ela assim disse para animar o marido e a si própria.

- Vamos, conte-me. Em que boates, e com que mulheres bonitas você gastou o dinheiro futilmente?

Ela falou de maneira leviana de propósito e, no mesmo instante, o marido demonstrou uma expressão de dor. Esta reação deixou-a um tanto satisfeita.

- Há várias - o marido respondeu reconstituindo-se a custo.

- Vamos, comece de onde quiser pela sua ordem.

Assim, o que o Sr. Aoki começou a contar no terraço onde penetrava o luar, era sobre a boate chamada $O$, onde ele ia quando não tinha muito dinheiro.

- Essa é uma boate em que trabalham duas irmãs, a mais velha é bonita e tem modos secos, e a nova, feia e molóide.

Essa boate, toda vez que aparecia por lá, era um lugar que dava a impressão de ter sido fechado há dois ou três dias. Ao ficar sentado na banqueta do balcão de modo indeciso, devido a essa impressão, aparece silenciosamente do fundo da boate a irmă mais nova, passados cinco minutos. Esse modo de aparecer estava sempre impregnado de uma sensação de niilismo. Quando se esperava que iria recusar a servir, enfiava-se vagarosamente para trás do balcão. Em seguida, arruma a sua volta e, só depois, pela primeira vez, olha o rosto do freguês. Dá a impressão de que está mal humorada ou entāo doente, mas, na realidade, esse é o comportamento normal dela, pois como prova, se por acaso um freguês disser: "Sempre quando venho, isto aqui está deserto como uma estação de trem que aparece nos filmes de faroeste", imediatamente ela ri alegremente, deixando os dentes brancos à mostra.

Quanto à irmã mais velha, sua preguiça é tamanha que, se não tiver muita disposição, não desce tão logo do primeiro andar.

Se um freguês entrasse entusiasmado porta adentro, sentir-se-ia escamoteado estranhamente pela atmosfera, como diria, depressiva ou sem ânimo, e, aturdido, ele não saberia se deveria retirar-se ou entrar. Era uma boate assim.

No entanto, a vantagem dessa boate é que os preços eram módicos. Como as donas agiam dessa rilaneira, isto $e$, não demonstravam vontade de trabalhar, era resultado natural que saísse barato enquanto não reclamarem.

O motivo dos inúmeros retornos do Sr. Aoki a esse lugar era logicamente o preço, mas estava mesmo era interessado na irmã 
mais velha.

Da primeira vez, quando foi levado por um amigo, achou que 0 rosto da mulher parecia com o da $M$, uma atriz do cinema francês, que tinha uma fisionomia real envolta numa atmosfera acentuadamente fantástica. Esse rosto tinha algo de amedrontador e, ao mesmo tempo, era profundamente romântico. Desde então nasceu em seu coração um vago desejo de passear pelas ruas desertas da noite, acompanhado por uma mulher assim, desejo este que foi realizado sem muita espera.

Comprou entradas para a competição internacional de natação, na qual participavam famosos nadadores norte-americanos, e entregou-lhe uma, a título de experiência. Achava que com certeza ela nåo apareceria, mas, chegando no local nessa noite, a mulher estava lá.

$\mathrm{Na}$ volta, percorreram duas boates e depois fizeram o tảxi correr sem destino pelas ruas da cidade mergulhada na noite. Não foi um passeio a pé, mas, podia-se dizer que o seu desejo tinha se realizado quase que totalmente.

Durante esse passeio, ela, ligeiramente melancólica, contou-Ihe sobre a sua infância vivida com o pai em Harbin; que quando chegava o verão ele a levava à llha do Sol e ela brincava à beira do Rio Sungari, de cor lamacenta, misturando-se entre as famílias russas; que na volta sempre entrava no restaurante que dava à avenida marginal onde, sentados na mesa perto da orquestra, o pai bebia vários copos de cerveja enquanto ela mordiscava um pedaço de pão preto, contemplando a superfície do rio ao entardecer.

Enquanto contava, ela ficou com o rosto recostado no ombro do Aoki. Ele achava que numa ocasião como esta é que tinha de beijá-la e não conseguia sequer prestar atenção às reminiscências dela, mas se tentasse beijar e ela ficasse zangada, estaria tudo perdido, e, se isso realmente acontecer, a situação poderia ficar deveras melindrosa. Assim, não conseguiu pôr a idéia em prática.

Depois disso, não teve outra oportunidade. Com isso, ele desperdiçou por várias vezes as entradas caríssimas de balé e de concertos musicais. Aoki observou-a por um certo tempo e concluiu que a muIher que foi assistir à competição de natação dos norte-americanos era realmente diferente da mulher de sempre. Se é que existe o que se chama de oportunidade, foi-se com aquela noite.

Depois dessa noite, ela se tornou uma fortaleza completamente inexpugnável. Toda vez que the via o sorriso mistico, ele ficava mais 
aflito em conquistá-la, mas não tinha a menor idéia sobre o que ela estaria pensando: se casará ou não com alguém, se gosta ou não de algum homem.

Havia muitos dias em que ela nem descia do andar superior, mesmo sabendo da presença do Aoki. Quando isso acontecia, ele ficava, mau grado seu, bebericando uma cerveja insossa, enquanto batia um papo vagaroso e sem nexo com a irmā mais nova.

O pior era quando nem ela nem a irmă mais nova apareciam e surgia, do fundo da boate, o rosto enrugado de uma velhota. Quando Aoki, demonstrando a sua insatisfação, perguntava sobre as irmãs, a velhota respondia que a irmã mais velha está com visitas no andar superior e a mais nova está deitada com dor de dente. Nessas ocasiōes havia vezes em que Aoki, para acalmar a sua irritação, se acomodava na banqueta do balcão e bebia a cerveja servida pela velhota.

Esta velha, não se sabia por quê, mostrava uma atitude de compaixão para com Aoki e nesses dias, demonstrava a sua simpatia cobrando apenas o preço de uma cerveja quando, na realidade, ele havia bebido três.

Sondava a velhota a respeito das irmãs e parecia que a irmã mais velha não possuía nenhum patrão, nem amante, dando crédito à veracidade da história que as irmãs contavam, de que o capital para abrir a boate fora financiado pelo pai delas. A velhota garantia que a visita do andar superior era um amigo íntimo do pai, não sendo ninguém suspeito.

Mesmo assim, o fato de ela e esse homem ficarem sozinhos num aposento particular do andar superior, conversando não se sabe sobre o quê, durante uma ou duas horas, desagradava-o muito.

Os fregueses dessa boate eram, em última análise, pessoas como Aoki que apareciam atraídas pela beleza da irmã mais velha. Aoki não era o único desprezado. Mas parecia que todos, mesmo insatisfeitos, não conseguiam esquecê-la e apareciam vez ou ou tra, como que casualmente e quando acontecia de se encontrarem, reconheciam-se mutuamente pelas suas maneiras. Por isso, mesmo sentindo-se um tolo, Aoki não conseguia deixar de freqüentar a boate.

O que ele achava incompreensivel era o fato de que apesar de a irmã mais velha ser possuidora de uma beleza difícil de ser encontrada em outros lugares, a boate, todas as vezes que ia, era muito pouco freqüentada, sem nunca ter conhecido uma verdadeira animação. Qual seria a razão disso?

O que ele contou à esposa não foi exatamente o narrado aqui. 
Mas fez um relato quase completo e semelhante a esse conteúdo.

- Só isso?

- Sim.

A esposa soltou uma risadinha.

- Até agora nunca me falou sobre esses assuntos.

- Pois só tenho levado "foras"

- Nem sempre, tenho certeza.

Ele não encontra palavras para responder.

- Deixe, nåo vou obrigá-lo a contar. Afinal, não creio que me contará a verdade. Tudo bem.

Ela percebe que foi realmente uma imprudente. $O$ marido fez mau uso do dinheiro da firma e, sendo descoberto, foi despedido. Por esse acontecimento ter-Ihe causado um grande choque, 0 pensamento dela havia se concentrado apenas nisso.

(Existe uma mulher. Foi por causa de uma mulher que o meu marido necessitou de uma grande soma de dinheiro.)

Esse pensamento que the ocorreu durante o relato do marido acertou-a como um raio.

Ela disfarçou o abalo que ocorreu no seu interior. $E$ quando o marido terminou de contar, pôs fim, com habilidade, às confissões dessa natureza.

O que o marido contou não tinha importância nenhuma. $O$ que ele tem para esconder são outros fatos, bem diferentes. $O$ caso que houve entre a mulher que morou em Harbin e que se parece com a $M$, atriz do cinema francés, deve ser uma espécie de subterfúgio. Ela percebeu isso com a sua susceptibilidade instintiva.

Se ela insistisse, talvez ele the contasse sobre outros casos amorosos que sugeririam uma leve apreensäo, e que na realidade nåo ofereciam nenhum perigo. Mas, não poderia cair nessa armadilha.

Sobre as coisas sem importância fala abertamente, como se estivesse confessando tudo. $E$, por trás de tudo, existe algo no qual o homem não ousa tocar nem com a ponta de uma agulha.

A cabeça da Medusa.

Ela nåo deve tentar espiar isso. Não deve persegu f-lo. Terá de fingir que nada sabe a respeito.

Quando pediu ao marido para contar alguma coisa, nem sonhava com tais possibilidades. Quando pediu que falasse sobre as boates, 
năo teve outra intenção a não ser de tentar animar a ambos.

No entanto, o que aconteceu? Inocentemente, ela construiu uma armadilha. E agora percebia que fizera cair a si mesma no próprio buraco.

Também no dia seguinte, ao entardecer, o Sr. Aoki saiu novamente em companhia dos meninos.

Enquanto prepara o jantar, ela se interroga continuamente até quando esta estranha rotina familiar irá prosseguir

O dinheiro para as despesas acabará daqui a duas semanas. O depósito bancário deles está sem fundo faz muito tempo. Tanto o marido como a esposa são daquelas pessoas que gastam o que ganham. Então, após esses dias', não haverá outro jeito a não ser ir se desfazendo dos pertences para comer. Será que dará para agüentar uns seis meses?

A familia dos pais dela, que antes da guerra tivera uma vida razoavelmente tranqüila trabalhando na importação e exportação, vive completamente na decadência, após o término da guerra.

Da parte do marido são três irmāos que estão na mesma situação - pobres assalariados ou funcionários públicos.

Nunca se preocuparam com o fato mas, uma vez em dificuldade como esta, ambos são praticamente órfãos solitários. Não possuem ninguém com quem possam contar.

Se não tivessem filhos, talvez tenham ainda recursos para ganhar a vida. Ela acha que saindo para trabalhar, poderia pelo menos, sustentar a si própria. Embora seja necessária muita coragem por parte dela, que não possui nenhuma habilidade. Porém, isso era algo impossível, tendo dois filhos ainda em idade escolar.

Seguindo esse raciocínio, conclui-se que a família não poderá mais viver unida, a não ser que o marido tenha êxito em encontrar outro emprego. Entretanto, haverá alguma firma disposta a acolher e sustentar um homem quarentão, casado e que fora despedido?

Ela começa a refletir. Há apenas uma semana, sobre o quê ela ficava pensando, enquanto preparava o jantar? Não consegue sequer lembrar.

Quando e por que essas transformações the sobrevieram? Por que a órbita de sua vida se desviou repentinamente e assim estão experimentando sofrimentos e medos injustificáveis? Qual é o deus que permitiu semelhante transformação absurda?

Os movimentos de acender o fogão, tirar a frigideira de cima dele, qual o significado de tudo isso? Por que as suas mãos vão se movi- 
mentando, desta maneira, como se fosse algo pré-determinado?

Por que será que está repetindo os mesmos movimentos que veio fazendo até hoje, dia após dia, como se fosse uma coisa natural? Será que isto não é um erro singular?

- Ela começa a sentir uma estranheza que, de repente, parece confundi-la toda.

E noite. Depois que as crianças foram dormir, o marido, bebendo $u$ ísque, contou à esposa o seguinte.

No prédio onde fica a minha firma, tem uma abertura ao lado do elevador de todos os andares, por onde se jogam as correspondências.

$E$ um buraco quadrado que vai do nono andar até o térreo. A parte dessa abertura que dá para o corredor é transparente e é feita de forma a poder enxergar as cartas caindo. Quando se passa em frente, vê-se às vezes os envelopes brancos caindo. Eles passam sem fazer nenhum barulho, pelo espaço que vai do teto do corredor até o résdo-chão. Há ocasiőes em que vejo os envelopes passarem continuamente.

Esse corredor do prédio é especialmente escuro. Quando não há ninguém por perto e vejo repentinamente algo branco passando rapidamente, levo um susto. Como explicar esta sensação? É como uma alma - como uma alma estranhamente triste.

Afastando-me um passo desse corredor estou no mundo humano, inexpugnável e sufocante, entalado em todas as salas. Expelido dessas salas e indo ao banheiro sozinho, deparo-me com isso na volta.

As vezes, pela manhã, devido à conveniência de algum serviço, chego à firma antes do horário normal.

Eu dou uma olhada na sala ainda deserta. Af, os homens que estão sempre sentados não estão presentes, mas sim as suas cadeiras. Quando fico olhando para uma dessas cadeiras, só pelo fato de o sujeito estar ausente, ela projeta mais nitidamente na minha mente as imagens vivas do formato da cabeça desse homem, do modo como movimenta os seus olhos, do movimento de sua boca quando fala, ou da expressão de suas costas.

O couro da cadeira onde se senta está mais lustroso, encardido por algo oleoso que é expelido pelo corpo da pessoa que se senta nela. É provavelmente algo parecido com o óleo que, no espaço de um longo tempo, foi espremido pela ira e nervosismo do homem, 
pelas reclamações e lamentações ou, ainda, pelo medo e insegurança. So consigo interpretar dessa maneira.

$\mathrm{Na}$ parte onde as costas se apóiam, e na maneira como ela está afundada, também é possivel ver o sentimento desse homem aqui na firma. Não é natural que o estado psíquico do homem que, queira ou não, vem aqui todos os dias, se transfira para a cadeira em que se senta?

Olho também, de mansinho, para a minha cadeira. Quão infeliz é essa cadeira. Uma pobre cadeira de um insignificante chefe substituto.

Em que momento será que eu fico sentado nela sem nenhum medo? Quando alguém tosse. subitamente nas minhas costas, o meu corpo parece saltar uns dez centímetros de tanto susto. Mas não é apenas eu que fico permanentemente amedrontado com alguma coisa.

Repare nas fisionomias das pessoas que entram nos escritórios. As pessoas que entram demonstrando animação e satisfação, estas são felizes. São dignas de felicitações. Porém, isso não acontece com a maioria das pessoas. Falo da fisionomia das pessoas de quando abrem empurrando a porta e põem os pés dentro das salas. $O$ que será que elas temem? Alguém em especial? Será que temem os superiores que os fiscalizam, tais como o presidente, o gerente, o chefe? Com certeza esse temor.deve existir também. Mas, não é só isso. Isso não passa de um dos fatores. Como prova, mesmo esses gerentes e chefes, quando passam pela porta, estão sentindo um certo temor no momento em que entram na sala abrindo a porta.

O que será que os fazem temer? Não são os indivíduos, e nem quaisquer motivos especificos. $E$ algo que os prendem, mesmo quando voltam para casa e se colocam entre a esposa e os filhos para descanso. Isso se manifesta até nos sonhos e vem intimidar os que dormem. Se durante a noite ficam sonhando com algo pavoroso e gemendo, é exatamente isso que está provocando os pesadelos.

Nas manhâs, ainda sem ninguém, quando olhava para as cadeiras, as mesas, a chapeleira e os cabides pendurados aí, eu me emocionava sem nenhum motivo aparente. Isso porque todos esses objetos representavam as pessoas que ai trabalhavam e me contavam coisas em demasiado.

- Minha mulher chorou ontem à noite também e ficou me chateando, dizendo: "Por favor, não perca a paciência, o salário pode ser pouco como agora, mas vou suportar o aperto. Por isso nåo faça nada precipitado e trabalhe com zêlo e afinco" E chorava. Até 
eu parei para pensar.

A cadeira do homem que assim me dizia está aĺ, comprimida junto à escrivaninha. Ao olhar essa cadeira, acabo por me lembrar claramente do tom da voz e até do sorriso envergonhado desse homem, quando desabafou-me seus lamentos que começou com os problemas financeiros da família.

- $O$ relato do marido termina aqui.

Nunca me contou sobre as boates, mas, será que alguma vez no passado havia confessado assim os sofrimentos que sentia em relação ao emprego?

Para ela, é novidade que o marido trabalhava com esse espírito. Se assim é, que descaso! Afinal, sobre o quê nós, marido e mulher que vivemos quinze anos numa mesma casa ficamos conversando durante todo esse tempo?

Mesmo que tenham transcorrido os dias em que a volta do marido era sempre às altas horas da noite e que de manhã saía apressado de casa, quer dizer que nós vivíamos à toa, sem conversar sobre um assunto importante sequer? O hábito de sairmos juntos nos dias de folga sempre foi mantido; e nessas ocasiões, o que será que ele me dizia e o que eu lhe perguntava? Ela jamais chegou a pensar que 0 marido tinha tais sentimentos em relação ao emprego. Apenas achava que ele, sem refletir muito, era uma pessoa que gosta de diversões e por isso nunca voltava antes da meia-noite.

Como o marido sempre se portava assim desde o tempo em que casaram, parece que isso foi desde $o$ in ício incutido nela, como uma idéia fixa. $O$ hábito de sair sempre aos domingos com a família era uma compensação à vida anti-familiar que levavam de segunda-feira a sábado, mas, mesmo assim, ela devia estar achando que isto era mais satisfatório do que a rotina de voltar cedo todos os dias e passar também os domingos ociosamente, sem distração.

Ao ouvir o marido, ela compreendeu que ele não voltava diretamente para casa, mesmo quando não tinha compromissos, porque ele sentia constantemente essa amargura em relação ao trabalho. Será que não conseguia sentir-se aliviado, mesmo voltando para casa? Isso significa que ficava amargurado ao ver a esposa e os filhos e esqueciase da amargura em companhia de mulheres nas boates e cabarés.

Se assim for, então, o que será que eu represento para o meu ma- 
rido? Subitamente, nascem no seu pensamento semelhantes dúvidas. Eu estava convencida de que éramos um casal mutuamente satisfeito e que confiávamos um no outro. No entanto, se não fui de nenhuma valia para consolar o meu marido, o que será que eu estava fazendo?

$O$ fato de não ter me contado, uma vez sequer, sobre a insegurança e a amargura do trabalho, não quer dizer que lá fora contava isso constantemente para alguém? Será que esse alguém não estaria por trás desse acontecimento?

Quando o marido falou sobre a boate das duas irmãs, a imagem dessa mulher relampejou como uma revelação. Essa idéia era portadora de um realismo assustador. Ela estremeceu e apressadamente tentou afugentar essa idéia, mas em vão.

Ter o marido em casa o dia inteiro deixava-a embaraçada no in $\mathrm{f}$ cio, mas, depois de levar essa vida durante uma semana, vinha-lhe a impressão de que assim era melhor.

Como seria bom se a família pudesse viver sem que o marido tivesse de sair todos os dias para trabalhar fora. Ela acha que isso seria normal se eles tivessem nascido na era primitiva.

O homem, quando se aborrecia, pegava a clava e safa; ao deparar com um animal selvagem corria, saltava em cima, lutava e o derrubava. Voltava trazendo esse animal nas costas e pendurava-o sobre o fogo. As mulheres e as crianças reuníam-se ao redor desse fogo e esperavam pelo assado. Se pudesse ter esse tipo de vida, é certo que seria bem melhor

Será que o costume social que determinou que o homem deve, todos os dias, vestir o terno, tomar o trem para ir ao local de trabaIho, e, ao anoitecer, retornar para casa exausto e mal-humorado, não é a causa primordial da infelicidade? Ela começou a raciocinar dessa maneira.

Na escuridão, o marido estava quieto, parecendo pensar em alguma coisa.

- Não consegue dormir?

Quando perguntou-the, ele, como quem quer negar, respondeu apressadamente:

- Não, já estou pegando no sono.

Depois, passados alguns instantes, disse:

- E que dormi bastante na sesta. 
- Quer que eu faça uma simpatia para dormir?

Dizendo isso, ela aproximou delicadamente o seu rosto sobre o rosto do marido, ficando a uma distáncia em que as pálpebras de ambos quase se tocam.

Não é uma simpatia. Isto é uma forma de carinho que ela inventara. Começa a pestanejar como se fosse unir as pontas das pestanas.

Com o movimento de suas pestanas levanta as do outro e dá leves sacudidas. E uma sensação estranha. Parece, por exemplo, dois passarinhos que tagarelam animados $e$ incansavelmente, como também pequenas fagulhas que se espalham do fogo no fim de um fogo de artifício.

Dentro da noite escura ela continua a pestanejar silenciosamente. Essas pestanas movimentam-se num ritmo que parecem querer consolar, acalmar, ou de repente, indagar e acusar.

O Sr. Aoki resolveu voltar ao trabalho.

Terminaram os dez dias de férias. Quando as crianças começaram a indagar: "Até quando o senhor está de férias?", já estava na hora de acabar com essa folga.

E também não se pode ignorar que as pessoas da vizinhança começaram a olhar para o Sr. Aoki de um modo desconfiado. Havia também algumas senhoras que perguntavam à esposa, como se quisessem sondar, quando esta saía para as compras.

Segredos desse tipo espalham-se com uma rapidez assustadora. Não morava nenhum companheiro de serviço na vizinhança, mas os comentários podiam ter sido transmitidos de qualquer lugar.

Em todo o caso, pensando nas crianças e levando em consideração que thes foi dito que estava de licença, ele não podia ficar para sempre nessa folga. E tinha também que começar a procurar outro emprego. Assim, o Sr. Aoki resolveu sair de casa à hora em que costumava sair de manhã para ir trabalhar.

Primeiro dia. Depois que o marido saiu, ela se sentiu inexplicavelmente fatigada. Na sua mente reflete-se a imagem do marido que vai andando sem destino pela cidade, sob o sol do fim de verão. A aflição do marido que caminha no andar incerto, misturando-se na multidåo, temendo encontrar algum conhecido, era transmitida diretamente para ela.

Talvez esteja olhando fixamente para a tela na escuriđâo do cine- 
ma, para evitar os olhares. Ou então, pode estar sentado num banco do terraço de algum shopping, observando as mães brincando com os filhos.

Repentinamente essas imagens desmoronam e aparece a figura do marido, de costas, subindo vagarosamente a escada de algum prédio de apartamento desconhecido. Ela tem a impressão de que todo o sangue do seu corpo se congela. (Cuidado! Não quero que você vá aíl Não, não, não. ।

Ela solta um grito. Mesmo assim, o marido vai subindo a escada vagarosamente. (Não pode! Se você for aí, será o fim! O fim!)

Essas alucinações perseguiam insistentemente a esposa que ficava em casa.

\section{Entardecer.}

Ela se descobre trabalhando na cozinha. Sente uma languidez pelo corpo todo, como se fosse uma doente febril.

Os meninos começam a brincar de beisebol na rua em frente à casa. Ouve-se a voz dos dois conversando.

- São bem rápidos.

- São índios mexicanos.

- Correm atrás dos impalas o dia inteiro e mesmo assim, não se cansam.

- É da tribo Tamafumala. Ta-ma-fu-ma-la.

- Seria tão bom se viessem ao Japão.

Essas frases sem nexo chegam aos ouvidos dela, intercaladas com o barulho da bola.

1 Será que ele vai voltar? Só quero que volte a salvo. Não me importo que seja um desempregado. Contanto que não se afaste desta casa

Ela pega o fósforo e acende o gás. E depois estica o braço e tíra uma panela da prateleira.

(Contanto que volte

A piscina está deserta e silenciosa.

No meio da superfície da água, sem as cordas de demarcação das raias, flutua a cabeça de um homem. 
Como amanhã começa o campeonato inter-colegial, o treino de hoje terminou duas horas mais cedo. $O$ instrutor, após ter dispensado as nadadoras, catava com os dedos dos pés a sujeira que se depositara no fundo da piscina.

Sopra a brisa da tarde que, de vez em quando provoca pequenas ondas na superfície da água.

Momentos depois, nos trilhos do outro lado da piscina aparece o trem. Aos olhos dos passageiros que estäo retornando para casa, após um dia de trabalho, aparece a piscina silenciosa. As nadadoras de sempre não estão e vê-se apenas a cabeça de um homem na superfície da água. 